documenting GCA or biopsy results were included in the PPV calculations. Algorithm 1, which identified the greatest number of patients $(n=896)$, yielded the lowest PPV of $60.7 \%$. Algorithms 4 and 5, which required disease-specific workups (temporal artery biopsy or chest imaging), mildly improved the PPV to $76.2 \%$ and $68.2 \%$, respectively. The PPV was highest in algorithm 3 (84.8\%), which required 2 or more diagnoses of GCA by a rheumatologist in addition to high dose steroid dispensing.

Table. PPV of Claims-based Algorithms

\begin{tabular}{lcccc}
\hline \multicolumn{5}{c}{ No. of patients } \\
\hline $\begin{array}{l}\text { Algorithm } \\
\#\end{array}$ & $\begin{array}{c}\text { Records } \\
\text { Identified }\end{array}$ & $\begin{array}{c}\text { Records } \\
\text { Reviewed }\end{array}$ & $\begin{array}{c}\text { Adequate } \\
\text { Records }\end{array}$ & PPV* (95\% Cl) $^{*}$ \\
\hline 1 & 896 & $446 \dagger$ & $206(46.2 \%)$ & $60.7 \%(53.7-67.4)$ \\
2 & 471 & 471 & $270(57.3 \%)$ & $78.6 \%(73.2-83.3)$ \\
3 & 220 & 220 & $125(57.4 \%)$ & $84.8 \%(77.3-90.6)$ \\
4 & 296 & 296 & $172(58.1 \%)$ & $76.2 \%(69.1-82.3)$ \\
5 & 47 & 47 & $26(55.3 \%)$ & $68.2 \%(48.2-85.7)$
\end{tabular}

* True positive cases included both definitive and probable GCA patients

†446 records were randomly selected for chart review.

Conclusion: A claims-based algorithm including two or more diagnosis codes for GCA by a rheumatologist separated by 7-30 days and high dose steroid dispensing (prednisone equivalent $\geq 40 \mathrm{mg} /$ day for $\geq 14$ days) can be a useful tool for identifying patients with GCA, allowing for future large real-world data studies. References:

[1] Crow RW et al. Giant cell arteritis and mortality. J Gerontol A Biol Sci Med Sci. 2009 Mar;64(3):365-9.

Acknowledgments: This study was supported by an investigator-initiated research grant from Genentech/Roche. The sponsor was given the opportunity to make non-binding comments on a draft of the abstract, but the authors retained the right of publication and to determine the final wording.

Disclosure of Interests: Hemin Lee: None declared, Sarah Chen Employee of: After finishing the work for this abstract, she has moved to work for Gilead., Sara Tedeschi: None declared, Paul Monach: None declared, Jun Liu: None declared, Attila Pethoe-Schramm Shareholder of: Current employee of F. Hoffmann-La Roche and own company stocks/stock options, Employee of: Current employee of F. Hoffmann-La Roche, Vincent Yau Shareholder of: Current employee of F. Hoffmann-La Roche/Genetech and own company stocks/stock options, Employee of: Current employee of F. Hoffmann-La Roche/Genetech, Seoyoung Kim Grant/research support from: Seoyoung $C$ Kim has received research grants from AbbVie, Roche, Bristol-Myers Squibb and Pfizer.

DOI: 10.1136/annrheumdis-2020-eular. 1125

\section{AB1247 ELEVATED SERUM COMPLEMENT (C3/C4) LEVEL AS AN INFLAMMATORY MARKER FOR INFECTION IN PATIENTS WITH FEVER: A RETROSPECTIVE STUDY}

Z.Y. Li ${ }^{1}$, J. Saleh ${ }^{2}$, S. Huang ${ }^{1}$, M. Elhassan ${ }^{3}$, C. Yuvienco ${ }^{4} .{ }^{1}$ University of California, San Francisco Fresno, Internal Medicine, Fresno, United States of America; ${ }^{2}$ A. T. Still University School of Osteopathic Medicine, Mesa, United States of America; ${ }^{3}$ St. Agnes Medical Center, Internal Medicine, Fresno, United States of America; ${ }^{4}$ UCSF Fresno, Rheumatology, Fresno, United States of America

Background: The functions of the complement system are to protect the host against infection, clearance of immune complexes, and regulate adaptive immunity after activation by C-reactive protein (CRP) or foreign cells. ${ }^{1} \mathrm{C} 3$ and C4 may increase up to 50 percent of baseline values as part of the acute-phase response, which is an expected host response for infection and injury. ${ }^{2}$

Objectives: We aimed to examine the correlation between elevated $\mathrm{C} 3 / \mathrm{C} 4$ levels and the underlying causes (infectious vs. non-infectious) of fever (subjective and/ or objective) in adults admitted to Community Regional Medical Center (CRMC). Methods: This is a retrospective study of C3/C4 level that was ordered in adult patients who were admitted to CRMC in April $1^{\text {st }}, 2018$ to September $30^{\text {th }}, 2018$ with fever. This was also analyzed in comparison to elevated lactic acid, erythrocyte sedimentation rate (ESR), and CRP level.

Results: Complement levels were ordered in 210 patients admitted to CRMC medicine or intensive care units. Among these patients, $28.09 \%(59 / 210)$ were diagnosed with various infectious diseases confirmed by gold standard methods (cultures, serology tests, computerized tomography, or magnetic resonance imaging), regardless of fever status during admission.

About $26.6 \%(56 / 210)$ had subjective or objective (temperature greater than 100.4 F or above), and $\mathbf{5 2}$ of them had complement levels (C3/C4) ordered with resulted in either normal or elevated. Within these $\mathbf{5 2}$ patients, lactic acid, ESR, and CRP were ordered in $\mathbf{3 3}, \mathbf{2 8}, \mathbf{2 5}$ of them respectively.
Table 1. Elevated $\mathrm{C} 3 / \mathrm{C}_{4}$ level vs. normal $\mathrm{C} 3 / \mathrm{C} 4$ level in detecting infection in fever patients when tested against gold standards.

\begin{tabular}{cccc}
\hline & $\begin{array}{c}\text { Patients with infectious } \\
\text { disease diagnosis }\end{array}$ & $\begin{array}{c}\text { Patients without infec- } \\
\text { tious disease diagnosis }\end{array}$ \\
\hline $\begin{array}{c}\text { Elevated C3 or C4 } \\
\text { or both (screen } \\
\text { test +) }\end{array}$ & 13 & 7 & $\begin{array}{c}\text { Positive predictive } \\
\text { value (PPV) } \\
=13 / 20=65 \%\end{array}$ \\
$\begin{array}{c}\text { Both normal C3 and } \\
\text { C4 (screen test -) }\end{array}$ & 8 & 24 & $\begin{array}{c}\text { Negative pre- } \\
\text { dictive value } \\
\text { (NPV) } \\
\end{array}$ \\
& & & $=15 / 32=48.9 \%$ \\
& Sensitivity=13/21=61.9\% & Specificity=24/31=77.4\% & \\
\hline
\end{tabular}

Table 2. Sensitivity, specificity, PPV, NPV, likelihood ratio positive (LR+), and likelihood ratio negative (LR-) among C3/C4, lactic acid, ESR, CRPI/ $\mathrm{CRPH}$ in detecting infection in patient with fever

\begin{tabular}{lcccc}
\hline C3/C4 (N=52) & $\begin{array}{c}\text { Lactic } \\
\text { Acid } \\
\mathbf{( N = 3 3 )}\end{array}$ & $\begin{array}{c}\text { ESR } \\
\mathbf{( N = 2 8 )}\end{array}$ & $\begin{array}{c}\text { CRPI/CRPH } \\
\text { (N=25) }\end{array}$ \\
\hline Sensitivity & $61.9 \%$ & $50 \%$ & $90 \%$ & $100 \%$ \\
Specificity & $77.4 \%$ & $91.3 \%$ & $11.1 \%$ & $11.8 \%$ \\
PPV & $65 \%$ & $71.4 \%$ & $36 \%$ & $34.8 \%$ \\
NPV & $48.9 \%$ & $80.8 \%$ & $66.6 \%$ & $100 \%$ \\
LR+ & 2.7 & 5.7 & 1.0 & 1.1 \\
LR - & 0.49 & 0.55 & 0.9 & 0 \\
\hline
\end{tabular}

Conclusion: Complement levels can be used as a rapid screening test to guide infection consideration as it correctly identified $61.9 \%$ of febrile patients with infection, and $77.4 \%$ who didn't have an infection. A positive screening test in itself still requires further investigation in the causes of fever to confirm the diag nosis since the PPV is $65 \%$. With the NPV of $48.9 \%$, a negative screening test is still not reassuring that the febrile patient doesn't have an infection. Our study demonstrated the potential utilization of the elevated complement level as an inflammatory marker for infectious etiology of fever, as it has better LR+ when compares to ESR and CRP with similar turnaround time.

This study helps educate providers to acknowledge the fact that complement level does not have to be limited to be used on autoimmune related disorders only. Further large pool studies will be necessary to further investigate the role of complement levels as part of the screening test in a patient with fever.

References:

[1] Walport. MJ. Complement. Second of two parts. N Engl J Med.2001 Apr 12; 344(15):1140-4. DOI: 10.1056/NEJM200104123441506

[2] Wen L, Atkinson JP, Giclas PC. Clinical and laboratory evaluation of complement deficiency. J Allergy Clin Immunol. 2004;113(4):585. DOI: 10.1016/j. jaci.2004.02.003

Characters from table content: 731

Disclosure of Interests: None declared

DOI: 10.1136/annrheumdis-2020-eular.1922

\section{AB1248 SYMPTOMS IN KNEE OSTEOARTHRITIS}

$\underline{Y}_{\text {. Liem }}{ }^{1}$, A. Judge ${ }^{1,2}$, K. Ourradi ${ }^{1,2}$, Y. Li ${ }^{1}$, M. Sharif ${ }^{1,2} .{ }^{1}$ University of Bristol, Bristol, United Kingdom; ${ }^{2}$ University of Bristol, Musculoskeletal Research Unit, Bristol, United Kingdom

Background: Osteoarthritis (OA) is one of the leading causes for disability in adults. The diagnosis of $O A$ is generally based on patient reported pain, other symptoms and radiographic changes which occur in late stages. There have been extensive research over the last 30 years to identify and validate molecular markers for early diagnosis of $\mathrm{OA}$ and a large range of potential biomarkers has been identified[1, 2]. However, most of these biomarkers are markers of structural and metabolic changes, and have poor correlation with pain and stiffness in knee OA. The publicly available data from the National Institute of Health Osteoarthritis Initiative (OAI) provides an opportunity to search for clinically useful biomarkers associated with the main symptoms in OA.

Objectives: To identify molecular biomarkers which are associated with the main symptoms of knee OA.

Methods: 600 participants from 4791 men and women aged 45 to 79 who were Kellgren \& Lawrence grade 1 or more were identified with biochemical mark ers data, radiographic and clinical features of OA. Nineteen biochemical markers measured in serum and/or urine were analysed for their association with primary clinical features of OA: Knee injury and Osteoarthritis Outcome Score (KOOS) pain and symptoms, and Western Ontario and McMaster Universities Osteoarthritis Index (WOMAC) pain and stiffness score. Patient level analysis 